\title{
DESENVOLVIMENTO TERRITORIAL E ALIMENTAÇÃO ESCOLAR: O CONSUMO NO VALE DO RIBEIRA E NO PONTAL DO PARANAPANEMA-SP
}

\author{
Deywison Tadeu Resende GONÇALVES ${ }^{1}$ \\ José Giacomo BACCARIN²
}

\section{Resumo}

O Programa Nacional de Alimentação Escolar (PNAE) tem como diretriz o desenvolvimento sustentável, busca articular a Segurança Alimentar e Nutricional com promoção de ocupação e renda no campo e a reaproximação entre produção e consumo. O objetivo deste artigo é apontar indícios dessa promoção por meio do PNAE aos Territórios da Cidadania Vale do Ribeira e Pontal do Paranapanema, Estado de São Paulo, considerando o período 2013-2015. Para isso, busca verificar o atendimento à garantia de $30 \%$ dos recursos repassados à agricultura familiar preconizados pelo Artigo 14 da Lei no 11.947 e identificar as formas de consumo promovidas na aquisição dos alimentos. A origem dos alimentos, o local produzido e o perfil dos fornecedores, pôde ser verificado por meio das prestações de contas disponibilizadas pelo Fundo Nacional de Desenvolvimento da Educação. A alocação interna dos recursos é superior aos que se deslocam para fora dos territórios, mas ainda é significativo o valor deste segundo montante e majoritária a participação de demais fornecedores. mentar.

Palavras-chave: Agricultura Familiar. Desenvolvimento Territorial. Segurança Ali-

\section{Abstract \\ Territorial development and school feeding: the consumption in Vale do Ribeira and Pontal do Paranapanema Pontal, São Paulo State}

The National School Feeding Program (PNAE) has as guideline sustainable development, seeks to articulate Food and Nutrition Safety with promotion of occupation and income in the field and the rapprochement between production and consumption. The aim of this article is to point out indications of this promotion through the PNAE to territories of Vale do Ribeira and Pontal do Paranapanema, State of São Paulo, considering the years 2013 to 2015 . For that, seeks to verify compliance with the guarantee of $30 \%$ of the resources passed to family agriculture, recommended by Artigo 14 of Lei $\mathrm{n}^{\circ}$ 11.947 and to identify the forms of consumption promoted in the acquisition of food. The origin of the food, the place of production and the profile of the suppliers, could be verified through the accounts provided by the National Fund for the Development of Education. The internal allocation of resources is higher than those that move out of the territories, but the value of this second amount is still significant and the participation of other suppliers is the majority.

Key words: Family Farming. Territorial Development. Food Safety.

\footnotetext{
1 Universidade Estadual Paulista "Júlio de Mesquita Filho". Mestrando no Programa de Pós-Graduação em Geografia, campus Rio Claro. E-mail: deywisont@hotmail.com

2 Universidade Estadual Paulista "Júlio de Mesquita Filho". Professor Adjunto do Departamento de Economia, Administração e Educação da Faculdade de Ciências Agrárias e Veterinárias, campus Jaboticabal. E-mail: baccarin@fcav.unesp.br
} 


\section{INTRODUÇÃO}

A atualidade das políticas públicas brasileiras para a agricultura familiar busca agir frente à insegurança alimentar e instituir mercados para a categoria. Soma-se a isso o recente debate e mudança do viés setorial para a perspectiva territorial de se pensar nas políticas.

No caso do Programa Nacional de Alimentação Escolar (PNAE), amparado pelo Artigo 14 da Lei n. 11.947, é garantido à agricultura familiar no mínimo $30 \%$ dos recursos repassados pelo Fundo Nacional de Desenvolvimento da Educação (FNDE) às Entidades Executoras (EExs), priorizando os assentados da reforma agrária, as comunidades tradicionais indígenas e as comunidades quilombolas (BRASIL, 2009).

O interesse do presente trabalho abarca o Programa Territórios da Cidadania (PTC) em seu desdobramento PNAE. Não se pretende esgotar todas as políticas abarcadas pelo primeiro, tendo em vista seu caráter transversal, mas sim, realizar apontamentos gerais sobre o PNAE à luz da perspectiva territorial. Para isso, foram selecionados dois territórios que já se incluem em nossas pesquisas, o Vale do Ribeira e o Pontal do Paranapanema.

Deste modo, o objetivo é apontar indícios de promoção de ocupação e renda nos municípios dos Territórios em questão, considerando a alimentação escolar como instrumento favorável ao desenvolvimento territorial. Nesta perspectiva, atribui-se as tarefas de verificar o atendimento à garantia de $30 \%$ dos recursos repassados à agricultura familiar preconizados pelo Artigo 14 da Lei no 11.947 e identificar as formas de consumo promovidas na aquisição dos alimentos em relação ao local de origem e o perfil do fornecedor.

Foi considerado o período 2013-2015 para análise das prestações de contas fornecidas virtualmente pelo FNDE. Com as informações de Cadastro de Pessoas Físicas (CPF) ou Cadastro Nacional de Pessoas Jurídicas (CNPJ) foi possível identificar a localidades desses fornecedores. Para o fornecimento via CPF foi consultada a Secretaria Especial de Agricultura Familiar e do Desenvolvimento Agrário (SEAD), na modalidade Extrato DAP - Pessoa Física. Os fornecimentos via CNPJ foram consultados na Receita Federal, Ministério da Fazenda.

Foi possível categorizar e quantificar os itens adquiridos da agricultura familiar e de outros fornecedores não caracterizados como tal, sobretudo os fornecedores comerciais. Também foi diferenciado, em cada uma das categorias, os alimentos adquiridos dos próprios municípios das prefeituras do território, de outros municípios do território, ou se foram adquiridos de fornecedores externos aos territórios. Esta medida nos indica certo grau de envolvimento com os princípios de sustentabilidade preconizados pelas diretrizes do PNAE.

Iniciamos o artigo retomando a literatura sobre as políticas públicas para a agricultura familiar no geral e sobre o PNAE em específico, atentando para os desafios enfrentados pelos envolvidos na execução do Programa. Posteriormente, apresentamos a análise dos dados referentes aos Territórios e ao período analisado, seguido pelas considerações finais.

\section{AGRICULTURA FAMILIAR NA PERSPECTIVA DO DESENVOLVIMENTO TERRITORIAL}

A adoção de um viés mais democrático como norteador de políticas públicas para a agricultura é recente no caso brasileiro. O reconhecimento da categoria da 
agricultura familiar já em meados da década de 1990 revela o início desse percurso, quando surge o Programa Nacional de Fortalecimento da Agricultura Familiar (PRONAF), pioneiro nesse cenário.

Não obstante, mesmo com a inserção do debate na esfera pública, as políticas sofreram mudanças substanciais desde quando iniciaram até o momento atual.

Grisa e Schneider (2014) descrevem o percurso recente distinguindo três gerações de políticas públicas que surgiram linearmente com o tempo, mas que não se excluem no presente, podendo se confrontar nas arenas públicas tendo em vista seus distintos referenciais. São elas: a geração de referencial agrícola e agrário; a geração de referencial assistencial e social; e a geração de referencial de construção de mercados para segurança alimentar e sustentabilidade ambiental.

O interesse por esta última geração decorre pela natureza das políticas ora analisadas, o PNAE e o PTC. Ambas se inscrevem num contexto de mudanças, da perspectiva setorial para a perspectiva territorial, no trato da questão segurança alimentar e sustentabilidade, tendo como foco a categoria da agricultura familiar.

\begin{abstract}
Essas mudanças se expressam pelo aprofundamento da reflexão crítica sobre o modelo dominante da modernização da agricultura, associado à concentração fundiária, pela progressiva formulação de políticas públicas voltadas para a reforma agrária, pelo combate à pobreza, pelo reconhecimento das comunidades tradicionais e pelo fortalecimento da agricultura familiar, pela construção de novas concepções de desenvolvimento propriamente rural, na perspectiva territorial, oposta ao enfoque setorial (WANDERLEY, 2014, p. 81-82).
\end{abstract}

A institucionalização de mercados revela a premência em se adotar estratégias políticas para a reprodução das camadas sociais da agricultura. Como assinala Abramovay (2007, p.31) os mercados não são formas acabadas e estão associados a "formas determinadas de interação correspondente a certas relações de forças entre grupos sociais". Na esteira desse processo está envolvida a questão alimentar em suas dimensões de produção e abastecimento.

A despeito da noção de segurança alimentar, desde sua emergência, estar basicamente relacionada à quantidade de alimentos fornecidos pela agricultura, atualmente percebe-se uma evolução conceitual. Retomando a posição tomada pela Organização das Nações Unidas para Agricultura e Alimentação (FAO), Ortega et al. (2007, p.185) apontam que a segurança alimentar e nutricional envolve "[...] uma quantidade de alimentos suficiente para suprir o mínimo recomendado por cada país, a qualidade e a salubridade da alimentação e, finalmente, a garantia de acesso digno a esses alimentos".

Nesta perspectiva, o desenvolvimento territorial pressupõe a dependência mínima de fatores e elementos externos, buscando com isso o máximo possível de autossuficiência econômica, política, social e ambiental, em suma, a sustentabilidade. Esta pauta-se na "[...] valorização das relações estreitas entre o ambiente e a sociedade com laços de experiências em ambos os sentidos, tendo a equidade social e ambiental como ideias fundamentais" (HOPWOOD; MELLOR; O'BRIEN, 2005, p.49, tradução nossa).

Conferir reconhecimento à agricultura familiar em seu âmbito territorial é dar crédito a essa alternativa de desenvolvimento mais equitativa, mais justa. Por isso que a recente reforma no PNAE, sobretudo com a criação do Artigo 14 no ano de 2009, se realiza por meio das pautas da universalidade no atendimento aos alunos da rede pública; da participação da comunidade no controle social; do apoio ao desen- 
volvimento sustentável; da oferta de alimentação adequada e sustentável; e da inclusão da Educação Alimentar e Nutricional no processo de ensino e aprendizagem (BRASIL, 2009).

Canal para comercialização dos alimentos de origem familiar, o PNAE estimula renda e ocupação para as populações territoriais, além da alimentação saudável para os escolares. Neste caso, a Educação Alimentar e Nutricional incluída nas diretrizes propõe a reflexão das formas de consumos promovidas pelo modo de vida urbano. Significa, portanto, a superação das opções industrializadas no espaço da escola (TRICHES, 2015).

Contudo, não há um perfil acabado de políticas públicas em vigência. Existem barreiras que ainda se sobressaem às potencialidades do PNAE e do PTC.

Primeiramente, na própria proposta de gestão participativa tem-se como pressuposto a existência de redes de interação entre as partes envolvidas em todo processo de discussão, elaboração e fiscalização das políticas, onde se confrontam diferentes visões de grupos locais, hegemônicos e populares, em sua relação com o Estado. As instituições que daí emanam podem não romper com a hegemonia dos poderes locais (NIERDELE, 2014) e com a burocratização de todo o processo que "[...] não é do conhecimento nem do quotidiano da maioria dos agricultores" (TRICHES; SCHNEIDER, 2012, p.101).

Decorrente desse primeiro ponto outros empecilhos tomam espaço dos ganhos aos grupos envolvidos. Exemplo é o desajuste entre a demanda e as condições dos produtores em relação ao grau de processamento dos alimentos e o número de pontos de entrega. Os produtos menos processados e o menor número de pontos de entrega são considerados condições favoráveis para os fornecedores da alimentação escolar. Em menor quantidade oferecida pela agricultura familiar, os produtos in natura estão mais ao alcance do fornecimento em comparação à exploração de gêneros de origem animal, considerando que na produção destes há a necessidade de adequação normativa e sanitária. No geral, o estímulo à produção e ao processamento é um desafio para as políticas (BACCARIN et al., 2012), bem como o aumento da organização dos produtores, visto que a alimentação escolar é adquirida, não raro, de agricultores mais articulados e organizados (SARAIVA et al., 2013).

Tendo em vista superar tais barreiras, os envolvidos lançam mão da estratégia de elaboração conjunta do cardápio escolar. Assim, a adequação da demanda escolar em relação à capacidade produtiva dos agricultores em consonância com a cultura local cria condições favoráveis de desenvolvimento territorial. Essa etapa pressupõe a ação conjunta dos gestores da alimentação escolar junto aos grupos de agricultores familiares e suas organizações.

\section{CONSUMO TERRITORIAL DO VALE DO RIBEIRA E DO PONTAL DO PARANAPANEMA}

O Território do Vale do Ribeira abarca 25 municípios, sendo 14 pertencentes à Região Administrativa (RA) de Registro (o próprio número total de municípios desta RA). Soma-se a eles dois municípios pertencentes à RA São Paulo (Juquitiba e São Lourenço da Serra), oito da RA Sorocaba (Apiaí, Barra do Chapéu, Iporanga, Itaóca, Itapirapuã Paulista, Ribeira, Ribeirão Branco, Tapiraí) e um da RA Baixada Santista (Peruíbe) (BRASIL, 2015c).

Ocupam uma área de $18.075,27 \mathrm{~km}^{2}$ que abriga 328.410 habitantes na cidade $(74,1 \%)$ e 114.821 no campo (25,9\%), totalizando 443.231 habitantes. Há 150 famí- 
lias assentadas em 13.716 hectares de área reformada e quatro projetos de reforma agrária. Existem também no Território 33 quilombos e 13 terras indígenas. Acerca da agricultura familiar, conta a categoria com 6.993 estabelecimentos e 14.225 pessoas ocupadas, totalizando 7.805 DAPs de Pessoas Físicas. Foram destinados R\$ 18.878.334,61 ao PRONAF no período 2013-2014 (BRASIL, 2015c).

Os recursos transferidos aos municípios do Território pelo FNDE relativos à execução do PNAE ultrapassaram oito milhões de reais em 2013, mas houve um pequeno decréscimo nos anos seguintes (Tabela 1 ).

\section{Tabela 1 - Gasto dos recursos repassados aos municípios do Território da Cidadania Vale do Ribeira divididos de acordo com a localidade e perfil dos fornecedores $(R \$)$}

\begin{tabular}{|c|c|c|c|}
\hline Local/Condição & 2013 & 2014 & 2015 \\
\hline \multicolumn{4}{|l|}{ Município } \\
\hline Agricultura Familiar & $1.552 .430,68$ & $1.445 .936,88$ & $1.292 .946,61$ \\
\hline No Fornecedores & 72 & 58 & 77 \\
\hline Demais Fornecedores & $1.768 .271,76$ & $2.186 .288,93$ & $2.336 .182,12$ \\
\hline No Fornecedores & 60 & 56 & 50 \\
\hline \multicolumn{4}{|l|}{ Território } \\
\hline Agricultura Familiar & $303.237,87$ & $190.535,26$ & $206.155,85$ \\
\hline No Fornecedores & 10 & 11 & 15 \\
\hline Demais Fornecedores & $1.385 .447,08$ & $1.694 .398,15$ & $1.767 .118,59$ \\
\hline No Fornecedores & 10 & 6 & 16 \\
\hline \multicolumn{4}{|l|}{ Externo } \\
\hline Agricultura Familiar & $347.577,35$ & $498.371,99$ & $259.814,96$ \\
\hline No Fornecedores & 22 & 26 & 5 \\
\hline Demais Fornecedores & $2.872 .432,55$ & $1.687 .337,95$ & $1.726 .546,47$ \\
\hline No Fornecedores & 52 & 54 & 54 \\
\hline Valor total (ano) & $8.229 .397,29$ & $7.702 .869,16$ & $7.588 .764,60$ \\
\hline
\end{tabular}

Fonte: FNDE. Org.: Deywison Tadeu Resende Gonçalves (2017).

Em cada ano, no mínimo, 30\% estaria reservado aos produtos da agricultura familiar. No geral, a média foi de 26,7\% em 2013, 27,7\% em 2014 e 23,1\% em 2015. É preciso atentar-se para a desigual distribuição da porcentagem entre os municípios, a utilização de mais de $30 \%$ por uns, e não aquisição por outros. No geral, 10 municípios atingiram o porcentual em 2013, 11 em 2014 e 10 em 2015.

O abastecimento por fornecedores próprios aos municípios foi o mais relevante. A quantidade gasta com fornecedores externos decresceu, mas manteve-se considerável no último ano, com quase dois milhões de reais. Mesmo que os demais fornecedores sejam sediados localmente ou territorialmente seus alimentos podem ser externos, devido ao caráter comercial. Já a agricultura familiar recebeu menores cifras em todas as localidades e, exceto externamente, teve o valor destinado a um número maior de agricultores. Isso pode decorrer do fato de ser permitida a cada agricultor a venda de no máximo R\$20 mil por Entidade Executora (BRASIL, 2015a).

As formas de consumo promovidas pelo PNAE podem ser verificadas por meio do tipo de produto ofertado na alimentação dos escolares. Assegura-se que a agricul- 
tura familiar esteja atrelada à Segurança Alimentar e Nutricional em vista de seus alimentos seguros e saudáveis (Tabela 2).

O abastecimento realizado pela categoria esteve, em praticamente todo o período analisado, atrelado aos produtos in natura. Como cultivo típico do Vale do Ribeira e ao mesmo tempo como alimento de mais fácil transporte e manuseio na alimentação escolar, a banana liderou os valores gastos. Outro destaque foi o palmito, segundo lugar nos gastos em 2015. Esse detalhe revela um ajustamento entre demanda e produção, com base na cultura territorial. Da cesta básica, apenas em 2014 aparece a mandioca na lista dos maiores gastos.

\section{Tabela 2 - Os 10 maiores gastos do Território da Cidadania Vale do Ribeira com produtos da Agricultura Familiar (R\$), 2013-15}

\begin{tabular}{lr|lr|lr}
\hline \multicolumn{2}{c|}{2013} & \multicolumn{2}{c}{ 2014 } & \multicolumn{2}{c}{2015} \\
\hline Produto & Valor (R\$) & Produto & Valor (R\$) & Produto & Valor (R\$) \\
Banana & $330.083,23$ & Banana & $415.291,77$ & Banana & $379.257,32$ \\
Mexerica & $147.395,99$ & Alface & $95.710,53$ & Palmito in natura & $97.428,37$ \\
Alface & $104.832,66$ & Palmito in natura & $90.932,20$ & Alface & $85.501,72$ \\
Goiaba & $72.163,90$ & Mexerica & $81.831,45$ & Goiaba & $79.011,46$ \\
Manga & $68.775,59$ & Goiaba & $77.473,18$ & Polpa de frutas & $77.423,16$ \\
Doce de banana & $60.588,35$ & Melancia & $67.567,30$ & Pepino & $59.552,15$ \\
Laranja & $55.006,33$ & Polpa de frutas & $63.325,98$ & Abobrinha & $44.947,99$ \\
Cenoura & $47.507,63$ & Abobrinha & $61.372,30$ & Caqui & $43.051,75$ \\
Palmito conserva & $46.649,90$ & Mandioca & $54.699,88$ & Abóbora & $42.787,28$ \\
Pepino & $44.362,43$ & Mand. s/ casca & $48.321,11$ & Tomate salada & $38.361,57$ \\
\hline
\end{tabular}

Fonte: FNDE. Org.: Deywison Tadeu Resende Gonçalves (2017).

Já nos alimentos provenientes das demais categorias tiveram maior participação os produtos de origem animal, que se caracterizam por cuidados específicos de produção, armazenamento e transporte. Estes incluem carnes, leite e laticínios, e em 2013 também ovos (Tabela 3).

Outro ponto a ser destacado é a contratação de serviços especializados em "fornecimento de alimentos preparados preponderantemente para empresas". Os itens referentes a esse fornecimento estão descritos como "outros gêneros alimentícios" e o valor em primeira posição em 2014 e 2015 condiz praticamente com a totalidade dos gastos da prefeitura de Peruíbe com serviços do gênero, que de $37,71 \%$ em aquisição da agricultura familiar em 2014 passou para nenhum gasto com a categoria em 2015.

Dos municípios que compõem o Território do Pontal do Paranapanema 31 pertencem à RA de Presidente Prudente (esta é composta por 53 municípios). A estes é somado o município de João Ramalho, pertence à RA de Marília (BRASIL, 2015b).

Com uma área de $18.392,16 \mathrm{~km}^{2}$ e população de 583.703 habitantes, residentes 523.829 na cidade $(89,7 \%)$ e 59.874 no campo $(10,3 \%)$, o Território Pontal do Paranapanema conta 12.315 estabelecimentos agropecuários familiares, com 27.984 pessoas ocupadas na agricultura familiar e 8.560 DAPs-Física. Além disso, existe uma área reformada de 142.427 hectares, com 6.060 famílias assentadas e 114 projetos de Reforma Agrária. Foram destinados R\$ 77.995.873,60 ao PRONAF no período de 2013-2014 (BRASIL, 2015b).

Os recursos destinados para a execução do PNAE no Pontal do Paranapanema aumentaram no período 2013-2015, chegando a mais de $\mathrm{R} \$ 10$ milhões no último ano (Tabela 4). 
Tabela 3 - Os 10 maiores gastos do Território da Cidadania Vale do Ribeira com produtos de Demais Fornecedores (R\$), 2013-15

\begin{tabular}{lr}
\hline \multicolumn{1}{c}{ 2013 } & \\
\hline Produto & Valor (R\$) \\
Leite de vaca integral, em pó & $264.320,24$ \\
Carne bovina, acém, sem gordura & $235.895,20$ \\
Carne moída & $213.132,26$ \\
Frango peito, sem pele & $177.450,52$ \\
Carne bovina, acém, moído & $158.295,65$ \\
Almôndega & $157.930,38$ \\
Feijão carioca & $151.333,64$ \\
Arroz tipo 1 & $149.052,73$ \\
Ovo de galinha & $124.829,99$ \\
Pão francês & $119.368,68$ \\
\hline \multicolumn{1}{c}{ 2014 } & \\
\hline Produto & Valor (R\$) \\
Outros gêneros não alimentícios & $1.084 .109,48$ \\
Carne bovina de 2a, resfriada/congelada & $498.212,74$ \\
Frango, peito, diversos cortes, resfriado/congelado & $233.839,15$ \\
Leite de vaca integral, em pó & $212.823,87$ \\
Bebida láctea, diversos sabores, mistura em pó & $180.719,90$ \\
Carne bovina de ${ }^{a}$, resfriada/congelada & $175.190,31$ \\
Pão, diversos tipos, farinha de trigo branca & $165.381,74$ \\
Maçã & $151.233,82$ \\
Frango, coxa e sobrecoxa, resfriado/congelado & $116.347,43$ \\
Iogurte, diversos sabores & $110.751,29$ \\
\hline \multicolumn{1}{c}{ 2015 } & \\
\hline Produto & Valor (R\$) \\
Outros gêneros não alimentícios & $1.173 .754,90$ \\
Carne bovina de 2a, resfriada/congelada & $556.027,91$ \\
Carne bovina de 1a, resfriada/congelada & $325.122,47$ \\
Pão, diversos tipos, farinha de trigo branca & $240.989,20$ \\
Bebida láctea, diversos sabores, mistura em pó & $183.506,98$ \\
Leite de vaca integral, em pó & $173.532,29$ \\
Maçã & $157.109,92$ \\
Iogurte, diversos sabores & $152.200,24$ \\
Frango, peito, diversos cortes, resfriado/congelado & $151.377,84$ \\
Frango, coxa e sobrecoxa, resfriado/congelado & $139.902,24$ \\
\hline Fonte: FNDE. Org.: Deywison Tadeu Resende & $(2017)$. \\
\hline
\end{tabular}

Fonte: FNDE. Org.: Deywison Tadeu Resende Gonçalves (2017).

O porcentual geral de gastos com gêneros alimentares de origem familiar foi de 21,22\% em 2013, 34,09\% em 2014 e 27,32\% em 2015, também distribuídos desigualmente entre os municípios, contando que em 2014 e 2015 apenas nove municípios atingiram o porcentual mínimo. Em 2013 foram quatro municípios que atingiram o porcentual exigido.

O gasto com fornecedores sediados localmente se sobressai, mas o fornecimento externo aumentou de forma acelerada chegando a quase $R \$ 2,6$ milhões em 2015.

A comparação em cifras entre agricultura familiar e demais fornecedores chega a ser favorável no nível local no ano de 2014, contudo o número de fornecedores 
chega a ser bem apartado e aumenta ainda mais no ano seguinte quando as cifras se revertem.

No nível territorial e externo os valores para a categoria familiar mantiveramse bem menores do que os destinados aos demais e a diferença no número de fornecedores entre as condições foi menor no Território do que externamente.

\section{Tabela 4 - Gasto dos recursos repassados aos municípios do Território da Cidadania Pontal do Paranapanema divididos de acordo com a localidade e perfil dos fornecedores $(R \$)$}

\begin{tabular}{|c|c|c|c|}
\hline Local/Condição & 2013 & 2014 & 2015 \\
\hline \multicolumn{4}{|l|}{ Município } \\
\hline Agricultura Familiar & $1.781 .803,75$ & $2.810 .953,45$ & $2.622 .355,09$ \\
\hline No Fornecedores & 162 & 183 & 242 \\
\hline Demais Fornecedores & $3.735 .781,34$ & $2.618 .073,22$ & $2.882 .436,86$ \\
\hline No Fornecedores & 116 & 94 & 86 \\
\hline \multicolumn{4}{|l|}{ Território } \\
\hline Agricultura Familiar & $396.755,18$ & $355.703,01$ & $321.556,55$ \\
\hline No Fornecedores & 36 & 35 & 54 \\
\hline Demais Fornecedores & $1.534 .028,57$ & $1.589 .291,30$ & $1.787 .579,93$ \\
\hline No Fornecedores & 38 & 30 & 32 \\
\hline \multicolumn{4}{|l|}{ Externo } \\
\hline Agricultura Familiar & $274.235,02$ & $57.904,50$ & $24.767,15$ \\
\hline No Fornecedores & 2 & 3 & 2 \\
\hline Demais Fornecedores & $1.043 .605,22$ & $1.773 .841,74$ & $2.562 .783,48$ \\
\hline No Fornecedores & 25 & 21 & 33 \\
\hline Valor total (ano) & $8.766 .209,08$ & $9.205 .767,22$ & $10.201 .479,06$ \\
\hline
\end{tabular}

Fonte: FNDE. Org.: Deywison Tadeu Resende Gonçalves (2017).

Assim como no Vale do Ribeira, o alimento fornecido pela agricultura familiar foi liderado em 2014 e 2015 pela banana. Isso deve-se ao seu fácil manuseio e pela sua distribuição entre as culturas locais (Tabela 5). Da cesta básica, em 2013 aparece o fornecimento de feijão carioca e em 2014 a mandioca.

Tabela 5 - Os 10 maiores gastos do Território da Cidadania Pontal do Paranapanema com produtos da Agricultura Familiar (R\$), 2013-15

\begin{tabular}{lc|lc|lr}
\hline \multicolumn{2}{c|}{ 2013 } & \multicolumn{2}{c|}{ 2014 } & \multicolumn{2}{c}{2015} \\
\hline Produto & Valor (R\$) & Produto & Valor (R\$) & Produto & Valor (R\$) \\
Suco de Laranja & $264.418,00$ & Banana & $381.008,88$ & Banana & $323.247,08$ \\
Alface & $189.845,34$ & Alface & $318.725,98$ & Alface & $253.953,26$ \\
Banana & $181.010,45$ & Tomate salada & $204.169,26$ & Tomate salada & $152.978,64$ \\
Leite past. & $161.652,75$ & Leite past. & $177.598,35$ & Leite past. & $151.512,55$ \\
Tomate c/ sem. & $146.848,60$ & Cheiro verde & $139.872,75$ & Cebola & $120.517,02$ \\
Bebida láctea & $132.047,45$ & Polpa de frutas & $139.137,42$ & Polpa de frutas & $120.337,80$ \\
Tomate salada & $101.714,10$ & Bebida láctea & $129.650,48$ & Leite, UHT & $107.632,00$ \\
Feijão carioca & $71.148,42$ & Couve manteiga & $111.864,66$ & Cheiro verde & $103.933,09$ \\
Pão francês & $70.209,00$ & Mexerica & $104.187,28$ & Mamão & $103.284,16$ \\
Cheiro verde & $64.386,74$ & Mandioca & $\mathbf{8 7 . 7 2 6 , 6 5}$ & Mexerica & $99.646,61$ \\
\hline
\end{tabular}

Fonte: FNDE. Org.: Deywison Tadeu Resende Gonçalves (2017). 
Contudo, aparecem entre os itens mais vendidos produtos de origem animal, leite e seus derivados. Isso decorre pela disseminação da pecuária no Pontal do Paranapanema e pela organização dos produtores em diversas associações e cooperativas, que em comparação ao Vale do Ribeira, recebeu mais recursos (Tabela 6). Considera-se também que o número de municípios do Pontal é maior que do Vale.

\section{Tabela 6 - Valores destinados às Cooperativas e Associações Privadas (R\$), 2013-15}

\begin{tabular}{lccc}
\hline Território & $\mathbf{2 0 1 3}$ & $\mathbf{2 0 1 4}$ & $\mathbf{2 0 1 5}$ \\
\hline Pontal do Paranapanema & $1.665 .987,68$ & $2.117 .457,32$ & $1.827 .116,80$ \\
Vale do Ribeira & $1.217 .095,84$ & $1.386 .420,15$ & $1.148 .637,64$
\end{tabular}

Fonte: FNDE. Org.: Deywison Tadeu Resende Gonçalves (2017).

Assim como no Vale do Ribeira, o fornecimento pelos demais também está atrelado ao consumo de produtos de origem animal. No Pontal do Paranapanema, a carne bovina foi a que se manteve no topo dos gastos com os Demais Fornecedores, chegando a mais de um milhão de reais no ano de 2015 (Tabela 7).

Tabela 7 - Os 10 maiores gastos do Território da Cidadania Pontal do Paranapanema com produtos de Demais Fornecedores ( $\$$ ), 2013-15

\begin{tabular}{lr}
\hline \multicolumn{1}{c}{$\mathbf{2 0 1 3}$} & \\
\hline Produto & Valor (R\$) \\
Carne bovina, coxão duro, sem gordura & $\mathrm{R} \$ 482.995,62$ \\
Carne bovina, acém, sem gordura & $\mathrm{R} \$ 298.983,37$ \\
Arroz tipo 1 & $\mathrm{R} \$ 292.917,42$ \\
Pão francês & $\mathrm{R} \$ 270.600,72$ \\
Frango, coxa e sobrecoxa, com pele & $\mathrm{R} \$ 223.303,16$ \\
Farinha de trigo & $\mathrm{R} \$ 165.717,03$ \\
Feijão carioca & $\mathrm{R} \$ 165.100,67$ \\
Carne bovina, paleta, sem gordura & $\mathrm{R} \$ 153.995,57$ \\
Carne bovina, patinho, sem gordura & $\mathrm{R} \$ 145.084,37$ \\
Salsicha & $\mathrm{R} \$ 137.555,61$ \\
\hline \multicolumn{1}{c}{$\mathbf{2 0 1 4}$} & \\
\hline Produto & $\mathrm{Valor}(\mathbf{R} \$ \mathbf{)}$ \\
Carne bovina de 2a, resfriada/congelada & $\mathrm{R} \$ 870.605,67$ \\
Carne bovina de 1a, resfriada/congelada & $\mathrm{R} \$ 622.640,33$ \\
Pão, diversos tipos, farinha de trigo branca & $\mathrm{R} \$ 444.118,92$ \\
Arroz tipo 1 & $\mathrm{R} \$ 295.647,67$ \\
Frango, coxa e sobrecoxa, resfriado/congelado & $\mathrm{R} \$ 263.299,71$ \\
Frango, peito, diversos cortes, resfriado/congelado & $\mathrm{R} \$ 216.186,44$ \\
Outros gêneros não alimentícios & $\mathrm{R} \$ 182.578,37$ \\
Salsicha, diversos sabores & $\mathrm{R} \$ 146.825,69$ \\
Leite pasteurizado & $\mathrm{R} \$ 122.180,91$ \\
Carne suína, diversos cortes & $\mathrm{R} \$ 114.618,39$ \\
\hline & $($ continua)
\end{tabular}


(continuação)

\begin{tabular}{lr}
\hline \multicolumn{1}{c}{$\mathbf{2 0 1 5}$} & \\
\hline Produto & Valor (R\$) \\
Carne bovina de $1{ }^{a}$, resfriada/congelada & $\mathrm{R} \$ 1.085 .438,18$ \\
Carne bovina de $2^{\mathrm{a}}$, resfriada/congelada & $\mathrm{R} \$ 848.924,10$ \\
Frango, coxa e sobrecoxa, resfriado/congelado & $\mathrm{R} \$ 545.960,55$ \\
Pão, diversos tipos, farinha de trigo branca & $\mathrm{R} \$ 486.979,15$ \\
Leite de vaca integral, em pó & $\mathrm{R} \$ 318.652,65$ \\
Arroz tipo 1 & $\mathrm{R} \$ 306.101,04$ \\
Frango, peito, diversos cortes, resfriado/congelado & $\mathrm{R} \$ 186.790,02$ \\
Salsicha, diversos sabores & $\mathrm{R} \$ 173.283,47$ \\
Leite pasteurizado & $\mathrm{R} \$ 172.551,48$ \\
Feijão carioca & $\mathrm{R} \$ 163.177,99$ \\
\hline
\end{tabular}

Fonte: FNDE. Org.: Deywison Tadeu Resende Gonçalves (2017)

O fornecimento de alimentos da cesta básica é considerável, arroz e feijão em 2013 e 2015 e feijão em 2014. O consumo de embutidos, como a salsicha, esteve presente em todo período analisado, assim como o leite e o pão.

\section{CONSIDERAÇÕES FINAIS}

Nos municípios abarcados pelos Territórios aqui analisados percebe-se que o índice mínimo dos $30 \%$ garantidos pelo Artigo 14 ainda se mostra tímido, sobretudo considerando que não são todos os municípios que atingem o percentual mínimo exigido pela lei.

À agricultura familiar, desse modo, acaba restando menores cifras em comparação aos demais fornecedores, que se caracterizam estritamente como comerciantes e não como produtores.

Percebe-se que a categoria familiar enquanto promotora de alimentação saudável e segura vem cumprindo esse papel na medida em que participa do processo de fornecimento. São incluídos na alimentação escolar produtos in natura e quando possível condizentes com a cultura local, como é o caso da banana e do palmito no Vale do Ribeira e da banana, leite e bebida láctea no Pontal do Paranapanema. Já os produtos oferecidos pelos demais fornecedores estão ligados às normatizações e exigências sanitárias decorrentes da produção de origem animal.

Com o pressuposto de conferir sustentabilidade na alimentação escolar é preciso também garantir a transferência mínima de recursos para fora do território e importação mínima de produtos de origem externa, sobretudo industrial.

É reforçado, contudo, a necessidade de articular os envolvidos na alimentação escolar, gestores escolares e grupos da agricultura familiar e suas organizações, para que o desempenho do Programa possa contribuir para as populações territoriais junto à valorização de suas potencialidades. 


\section{REFERÊNCIAS}

ABRAMOVAY, R. Para uma teoria dos estudos territoriais. In: ORTEGA, A. C.; FILHO, N.A. (Org.). Desenvolvimento Territorial, Segurança Alimentar e Economia Solidária. Alínea editora. Campinas, 2007. Capítulo 1, p.19-37.

BACCARIN, J. G. et al. Agricultura familiar e alimentação escolar sob a vigência da Lei 11.947/2009: adequação das chamadas públicas e disponibilidade de produtos no estado de São Paulo em 2011. In: Congresso da Sociedade Brasileira de Economia, Administração e Sociologia Rural, 50., 2012, Vitória (ES). Anais... Vitória: SOBER, 2012.

BRASIL. Ministério da Educação. Lei no 11.947, de 16 de junho de 2009. Dispõe sobre o atendimento da alimentação escolar e do Programa Dinheiro Direto na Escola aos alunos da educação básica; e dá outras providências. Diário Oficial da União, Brasília, DF, 17 jun. 2009. Seção 1, p.2.

BRASIL. Ministério da Educação. Resolução no 4, de 2 de abril de 2015. Altera a redação dos artigos 25 a 32 da Resolução/CD/FNDE no 26, de 17 de junho de 2013, no âmbito do Programa Nacional de Alimentação Escolar (PNAE). Diário Oficial da União, Brasília, DF, 08 abril 2015a. Seção 1, p. 21.

BRASIL. Ministério do Desenvolvimento Agrário. Secretaria de Desenvolvimento Territorial. Perfil Territorial do Pontal do Paranapanema - SP, maio/2015b. Disponível em: < http://sit.mda.gov.br/download/caderno/caderno_territorial_ 073_Pontal\%20Do\%20Paranapanema\%20-\%20SP.pdf>. Acesso em: 20 março 2016.

BRASIL. Ministério do Desenvolvimento Agrário. Secretaria de Desenvolvimento Territorial. Perfil Territorial do Vale do Ribeira - SP, maio/2015c. Disponível em: $<\mathrm{h} \mathrm{t} \mathrm{t} \mathrm{p} \mathrm{:} \mathrm{/} \mathrm{/} \mathrm{s} \mathrm{i} \mathrm{t.} \mathrm{m} \mathrm{d} \mathrm{a.gov.} \mathrm{br/dow} \mathrm{n} \mathrm{lo} \mathrm{a} \mathrm{d} \mathrm{/} \mathrm{c} \mathrm{a} \mathrm{d} \mathrm{e} \mathrm{r} \mathrm{n} \mathrm{o} \mathrm{/}$ caderno_territorial_100_Vale\%20do\%20Ribeira\%20-\%20SP.pdf>. Acesso em: 20 março 2016.

GRISA, C.; SCHNEIDER, S. Três gerações de políticas públicas para a agricultura familiar e formas de interação entre sociedade e estado no Brasil. Revista de Economia e Sociologia Rural, Piracicaba, v. 52, s.1, p.125-146, 2014.

HOPWOOD, B; MELLOR, M.; O'BRIEN, G. Sustainable Development: mapping different approaches. Sustainable Development [Online], v. 13, n. 1, p.38-52, fev./2005.

NIEDERLE, P. A. Política local e a trama das relações de poder no desenvolvimento territorial. In: CAVALCANTI, J. S. B.; WANDERLEY, M. N. B.; NIEDERLE, P. A. (Org.). Participação, território e cidadania: um olhar sobre a política de desenvolvimento territorial no Brasil. Recife: Editora UFPE, 2014. Capítulo 4, p.104-135.

ORTEGA, A. C. et al. Segurança Alimentar: evolução conceitual e ação das políticas públicas na América Latina. In: ORTEGA, A. C. (Org.). Território, políticas públicas e estratégias de desenvolvimento. Campinas, SP: Alínea, 2007. Capítulo 7, p. 175-206.

SARAIVA, E. B. et al. Panorama da compra de alimentos da agricultura familiar para - Programa Nacional de Alimentação Escolar. Ciência e Saúde Coletiva, Rio de Janeiro, v. 18 , n. 4, p.927-936, abr./2013.

TRICHES, R. M. Promoção do consumo alimentar sustentável no contexto da alimentação escolar. Trabalho, Educação e Saúde, Rio de Janeiro, v.13, n.3, p.757-771, set./ dez. 2015. 
TRICHES, R. M.; SCHNEIDER, S. Desestruturar para construir: interfaces para a agricultura familiar acessar o programa de alimentação escolar. Estudos Sociedade e Agricultura, Rio de Janeiro, v. 20, n. 1, p.66-105, abr./2012.

VILLAR, B. S. et al. Situação dos municípios do estado de São Paulo com relação à compra direta de produtos da agricultura familiar para o Programa Nacional de Alimentação Escolar (PNAE). Revista Brasileira de Epidemiologia, São Paulo, v. 16 , n. 1 , p. 223-226, mar./2013.

WANDERLEY, M. N. B. Gênese da abordagem territorial no Brasil. In: CAVALCANTI, J. S. B.; WANDERleY, M. N. B.; NIEDERLE, P. A. (Org.). Participação, território e cidadania: um olhar sobre a política de desenvolvimento territorial no Brasil. Recife: Editora UFPE, 2014. Capítulo 3, p.80-103. 